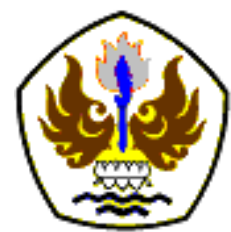

INFOMATEK

Volume 22 Nomor 2 Desember 2020

\title{
RANCANG BANGUN ALAT UJI BIOMASSA UNTUK MENGETAHUI EMISI GAS BUANG SEBAGAI SUMBER ENERGI TERBARUKAN
}

\author{
Aa Santosa*), Farradina Choria Suci \\ Program Studi Teknik Mesin \\ Fakultas Teknik-Universitas Singaperbangsa Karawang
}

\begin{abstract}
Abstrak: Terdapat alat yang diperlukan agar mampu memberikan informasi mengenai karakteristik dari emisi gas buang pada pembakaran biomassa sehingga bisa menentukan jenis kayu yang paling efektif untuk digunakan sebagai bentuk energy alternative dan terbarukan terbarukan. Pada kajian ini dirancang dan dibuat sebuah alat untuk memberikan informasi emisi gas buang kayu, yaitu sebuah tungku (furcane) dengan menggunakan material semen tahan api untuk ruang bakar yang dilapisi bata tahan api, dan casing plat baja sebagai isolator. Tungku dilengkapi tambahan komponen kipas pada pintu depan untuk membantu mengalirkan udara saat pembakaran langsung dan sensor gas analyzer untuk mendapatkan data emisi gas buang yang dipasang pada saluran keluar udara. Tungku (furnace) yang dibuat mampu mencapai suhu $800^{\circ} \mathrm{C}$ dari temperatur $32^{\circ} \mathrm{C}$ dalam waktu 360 menit. Pengujian dilakukan untuk melihat karakteristik emisi gas buang dengan menggunakan jenis kayu Mahoni, Nangka dan Jati, karena jenis kayu ini banyak sekali tumbuh di Indonesia. Hasil pengujian menunjukkan bahwa kayu Mahoni memiliki kadar air 12,24 \%, kadar zat terbang 83,5 $\%$, kadar abu 0,57 \%, dan kadar karbon terikat 3,69 \%. Kayu Nangka memiliki kadar air 13,34 \%, kadar zat terbang $82,5 \%$, kadar abu 0,25 \%, dan kadar karbon terikat 3,64 \%. Kayu Jati memiliki kadar air 42,22 \%, kadar zat terbang $71,6 \%$, kadar abu $0,35 \%$, dan kadar karbon terikat 3,71\%. Berdasarkan pengujian ini, didapatkan bahwa kayu Mahoni ini mudah menyala jika dibakar, dengan kadar air paling sedikit dihasilkan.
\end{abstract}

Kata kunci: Karakteristik, Emisi Gas Buang, Biomassa, Furnace, Gas Analyzer

\section{PENDAHULUAN}

Konsumsi energi telah menjadi bagian dari kebutuhan hidup manusia sehari-hari, terutama konsumsi energi yang berbahan dasar fosil. Menurut data BPPT-OEI (Sugiyono [1]), Sumber daya energi banyak dihasilkan dari fosil seperti minyak bumi, gas bumi dan batubara.

*) aa.santosa@ft.unsika.ac.id

Pertama diterima: 8 September 2020

Direvisi: 13 November 2020

Disetujui untuk publikasi: 14 November 2020
Emisi dari hasil pembakaran energi bahan bakar, baik itu berupa padat, cair, maupun gas dapat menimbulkan efek negatif pada lingkungan salah satunya meningkatnya suhu permukaan bumi, sehingga perlu energi dan cara pemanfaatan energi tersebut sehingga proses pembakaran yang memiliki kualitas baik dan ramah lingkungan [1]. Energi Baru Terbarukan (EBT) merupakan energi yang dapat menjadi solusi dari permasalahan ini, 
karena energi ini memiliki potensi pembaruan yang cepat dan emisi yang dihasilkan lebih ramah dari energi fosil yang ada. Salah satunya yaitu memanfaatkan energi yang berasal dari tumbuhan atau tanaman yang dapat dibakar dan bersifat terbarukan, dimana kadar karbondioksida, sulfur yang rendah (Mulyasari [2]).

Biomassa dihasilkan dari tanaman, hewan dan mikroorganisme. Indonesia banyak menghasilkan energi yang bisa dimanfaatkan dengan teknologi sederhana sehingga bisa menghasilkan energi terbarukan. Namun sebelum dapat digunakan sebagai bahan bakar perlu dilakukan kajian terhadap karakteristik dan emisi gas buang dari bahan bakar biomassa tersebut [2].

Bahan baku biomassa yang sangat mudah ditemui adalah kayu. Kajian tersebut dilakukan menggunakan analisa proksimat untuk mengetahui kadar air (moisture content), zat terbang (volatile matter), abu (ash), dan karbon tetap (fixed carbon). Selain itu, perlu juga dilakukan analisa terhadap hasil proses pembakaran pada tumbuhan atau kayu yang berlangsung seperti karbon monoksida (CO), sulfur dioksida $\left(\mathrm{SO}_{2}\right)$, dan nitrogen oksida (NOx).

Pengujian terhadap karakteristik dan emisi gas buang bertujuan untuk mengetahui jenis kayu yang tepat untuk digunakan sebagai biomassa bahan bakar alternatif di masa yang akan datang. Berdasarkan uraian diatas maka dibutuhkan sebuah alat yang mampu memberikan informasi mengenai karakteristik dan emisi gas buang pada biomassa, maka dirancang sekaligus dibuat sebuah tungku untuk membakar kayu yang diuji (Rahmat [5]).

\section{METODOLOGI}

\subsection{Diagram Alir Penelitian}

Penelitian ini dilakukan dalam tiga tahap, yaitu tahap perancangan, tahap pembuatan, dan tahap pengujian. Tahap perancangan meliputi tahap pengumpulan data literatur, pencarian data material yang digunakan, dan diskusi dengan berbagai narasumber.

Pembuatan alat ini dilakukan di laboratorium Proses produksi, Fakultas Teknik, Universitas Singaperbangsa Karawang. Setelah tahap pembuatan selesai, maka tahap selanjutnya adalah tahap pengujian.

Pengujian dilakukan melalui dua tahap, yaitu pengujian dengan menggunakan analisis proksimat untuk mengetahui karakteristik dari biomassa menggunakan furnace dan pengujian dengan menggunakan gas analyzer untuk mengetahui hasil proses pembakaran. 


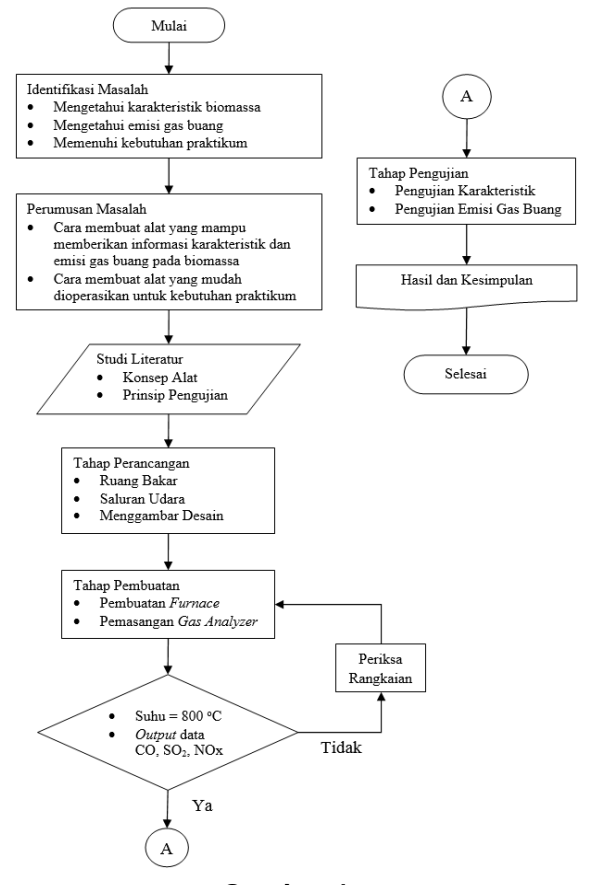

Gambar 1.

Diagram Alir

\subsection{Desain Perancangan}

Sebelum membuat alat, terlebih dahulu dibuat desain alat yang akan dibuat. Pembuatan desain ini menggunakan software SolidWorks.

\subsection{Pembuatan Furnace}

Proses Pembuatan alat uji dilakukan setelah semua data tersedia. Tahap pembuatan alat diantaranya perakitan rangka utama, pemasangan isolator bata tahan api dan semen tahan api, casing, pintu depan, pintu geser depan, pintu geser atas, dan pemasangan gas analyzer.

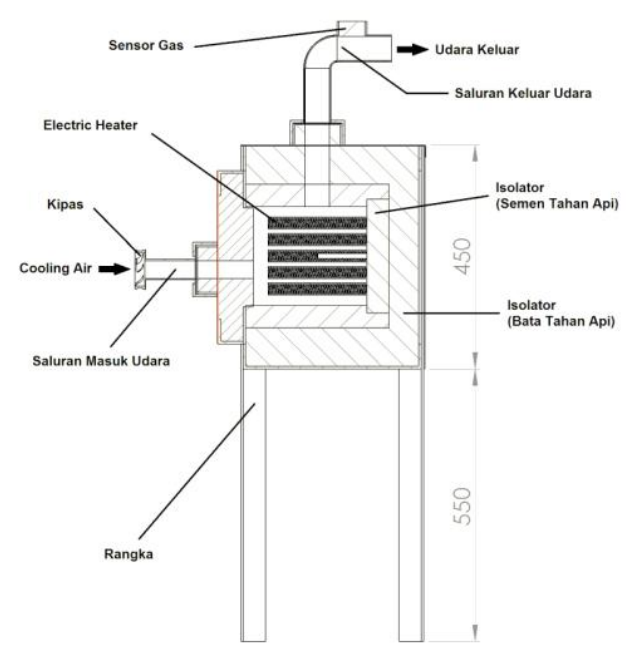

Gambar 2.

Rancangan Furnace

Berdasarkan spesifikasi yang telah ada, selanjutnya tahap dimulai dari pembuatan ruang bakar dari material semen tahan api yang dicor dengan dimensi panjang 200 mm, lebar $200 \mathrm{~mm}$, tinggi $200 \mathrm{~mm}$, dan tebal 45 $\mathrm{mm}$. Material semen tahan api dipilih karena material ini mengandung unsur silica, carbida, dan unsur lain yang mampu tahan sampai temperatur $1400{ }^{\circ} \mathrm{C}$. Pada saat pengecoran pada bidang bagian dalam diberikan rongga untuk pemasangan pemanas elektrik [3].

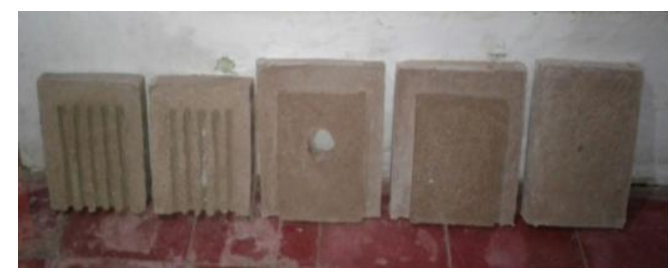

Gambar 3.

Dinding Furnace 
Tahap selanjutnya menyiapkan bata tahan api sebagai bahan isolator. Pemilihan material ini dikarenakan kemampuannya sama dengan semen tahan api yaitu mampu tahan sampai temperatur $1200{ }^{\circ} \mathrm{C}$. Kemudian pembuatan rangka menggunakan baja siku ukuran $50 \mathrm{~mm}$ x $50 \mathrm{~mm}$ x $5 \mathrm{~mm}$ sesuai dengan desain yang telah dibuat (Gustar [4]).

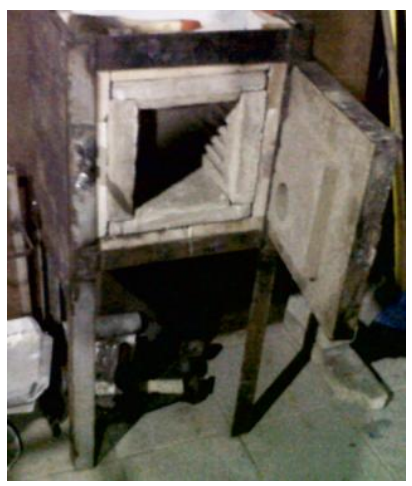

Gambar 4.

Ruang Bakar Furnace

Pemanas elektrik dipasang pada bagian rongga ruang bakar yang telah dibuat. Pemanas elektrik ini dirangkai paralel agar suhu yang dibutuhkan dapat tercapai dengan cepat. Sistem pemanas elektrik tersebut kemudian disambung pada sistem kontrol temperatur agar suhu yang dibutuhkan dapat diatur sesuai dengan kebutuhan pengujian (Jihan [5]). Sistem kontrol menggunakan kontrol dimmer potensiometer AC 4000 Watt dengan pengaman MCB arus maksimal 20 Ampere.
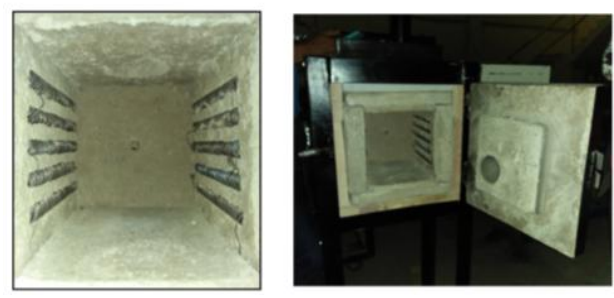

\section{Gambar 5.}

Pemanas Elektrik

\subsection{Pemasangan Gas Analyzer}

Alat ini dirakit di dalam panel box bersama dengan sistem kontrol listrik, bagian sensor gas dipasang pada pipa saluran keluar agar dapat mendeteksi kadar emisi yang dihasilkan dari proses pembakaran yang terjadi saat pengujian. Selain pemasangan sensor gas, juga dipasang kipas pada bagian saluran masuk untuk membantu proses pembakaran yang terjadi dalam ruang bakar [5].

Setelah seluruh komponen terpasang, maka alat uji karakteristik dan emisi gas buang telah selesai dibuat

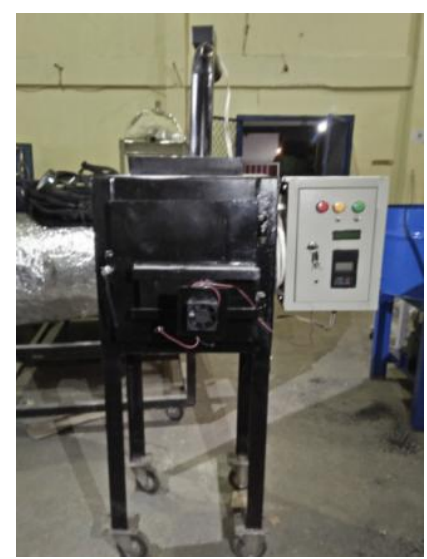

Gambar 6

Furnace alat pembakaran Biomassa 


\subsection{Tahapan Pengujian}

Alat yang digunakan untuk melakukan proses karakterisasi antara lain furnace, dan cawan porselin. Proses pengujian mengikuti prosedur berdasarkan standar ASTM (Badan Standardisasi Indonesia [6]). Berikut merupakan prosedur pengujian yang dilakukan:

1. Kadar Air (Moisture)

Prosedur pengujian jumlah air yang terkandung dalam kayu mengacu pada standar ASTM E 871. Metode ini dilakukan dengan memasukan serbuk kayu sebanyak 1 gram dalam furnace selama 24 jam pada temperatut furnace $105^{ \pm 30 C}$ atau hingga berat keringnya konstan.

$$
\text { kadar air }(\%)=\frac{\text { massa sample }- \text { massa kering }}{\text { massa sample }} \times 100 \%
$$

\section{Kadar Zat Terbang (Volatile Matter)}

Prosedur pengujian kadar zat terbang mengacu pada standar ASTM E 872. Metode ini dilakukan dengan menimbang serbuk kayu sebanyak 1 gram dalam cawan porselen. Kemudian, cawan porselen yang berisi serbuk kayu dimasukkan kedalam furnace dan dipirolisis pada suhu $800{ }^{\circ} \mathrm{C}$ selama 7 menit. Sample didinginkan dalam desikator, kemudian sample yang telah dingin kemudian ditimbang.

$$
\text { Kadar zat terbang }(\%)=\frac{\text { massa yang hilang }}{\text { massa sample }} \times 100 \%
$$

3. Kadar Abu (Ash)
Kadar abu merupakan kandungan mineral dalam bahan yang merupakan sisa dari proses pembakaran sample [2]. Prosedur pengujian kadar abu mengacu pada standar ASTM D 1102. Metode ini dilakukan dengan memasukkan serbuk kayu sebanyak 2 gram ke dalam cawan porselen dan diabukan dalam furnace pada suhu $600{ }^{\circ} \mathrm{C}$ selama 6 jam. Sample didinginkan dalam desilator, kemudian sample yang telah dingin kemudian ditimbang. Kadar abu $(\%)=\frac{\text { massa abu }}{\text { massa sample }} \times 100 \%$

\section{Kadar Karbon Terikat (Fixed Carbon)}

Kadar karbon terikat merupakan kandungan karbon dalam sample setelah penghilangan zat terbang dan abu

Kadar $f c=100 \%$ - kadar zat terbang - kadar abu - kadar air

\subsection{Pengujian Emisi Gas Buang}

Pengujian ini bertujuan untuk mengetahui emisi yang dihasilkan dari pembakaaran biomassa agar dapat dipelajari potensi pemanfaatan biomassa yang baik. Data yang diambil dari pengujian berupa data karbon monoksida (CO), sulfur dioksida $\left(\mathrm{SO}_{2}\right)$, dan nitrogen oksida (NOx).

Berikut merupakan prosedur pengujian yang dilakukan

1. Sample biomassa yang diuji dimasukkan kedalam cawan porselin, kemudian sample tersebut dibakar langsung oleh pemantik 
api. Setelah sample terbakar maka dimasukkan kedalam ruang bakar furnace.

2. Biarkan sample terbakar sampai hampir habis, kemudian hidupkan kipas yang dikontrol kecepatannya sesuai kebutuhan dan gas analyzer untuk membaca hasil emisi yang dihasilkan dari pembakaran biomassa

3. Data hasil pengujian ditampilkandilayar LCD.

\section{ANALISIS DAN PEMBAHASAN}

Dalam Pengujian yang dilakukan ini menggunakan tiga jenis kayu yaitu Kayu Mahoni, Kayu Nangka dan katu Jati.

\subsection{Pengujian Emisi gas buang.}

Sample kayu dibakar langsung dalam cawan porselen kemudian dimasukkan kedalam ruang bakar. Kemudian gas buang yang keluar melalui cerobong akan dibaca oleh sensor gas analyzer.

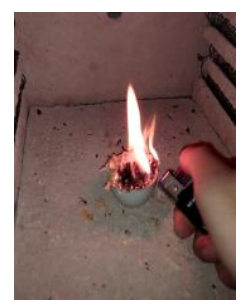

Gambar.7.

Pembakaran langsung serbuk kayu

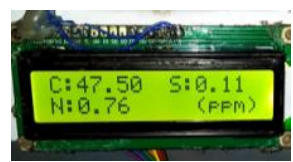

Gambar.8.

Hasil pembacaan emisi gas buang
Tabel 1. Hasil Emisi Gas Buang

\begin{tabular}{|c|c|}
\hline Jenis Kayu & Mahoni \\
\hline Jenis Emisi Gas Buang & Nilai Emisi $(\mathrm{ppm})$ \\
\hline Karbon Monoksida $(\mathrm{CO})$ & 47,50 \\
\hline Sulfur Dioksida $\left(\mathrm{SO}_{2}\right)$ & 0,11 \\
\hline Nitrogen Oksida (NOx) & 0,76 \\
\hline Jenis Kayu & Nangka \\
\hline Jenis Emisi Gas Buang & 57,01 \\
\hline Karbon Monoksida (CO) & 0,16 \\
\hline Sulfur Dioksida (SO $)$ & 13,21 \\
\hline Nitrogen Oksida (NOx) & Jati \\
\hline Jenis Kayu & \\
\hline Jenis Emisi Gas Buang & 74,78 \\
\hline Karbon Monoksida $(\mathrm{CO})$ & 0,37 \\
\hline Sulfur Dioksida (SO $\left.{ }_{2}\right)$ & 22,36 \\
\hline Nitrogen Oksida (NOx) &
\end{tabular}

\subsection{Pengujian Karakteristik}

Pengujian karakteristik dilakukan menggunakan analisis proksimat untuk mengetahui kadar air, zat terbang, kadar abu, dan karbon terikat, dengan menggunakan persamaan [2], [4], [5], [6].

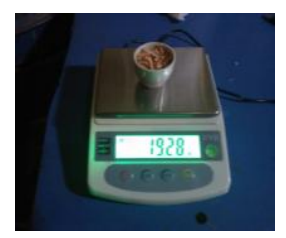

Gambar 9.

Penimbangan sample kayu

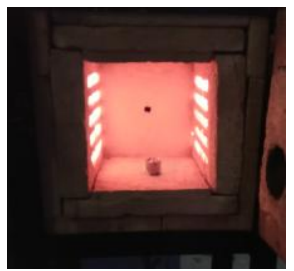

Gambar 10.

Pemanasan sample untuk analisis proksimat 
Tabel 2 Hasil Pengujian Karakteristik

\begin{tabular}{|l|c|}
\hline \multicolumn{2}{|c|}{ Jenis Kayu Mahoni } \\
\hline Jenis Kadar & Persentase \\
\hline Kadar Air & $12,24 \%$ \\
\hline Kadar Zat Terbang & $83,5 \%$ \\
\hline Kadar Abu & $0,57 \%$ \\
\hline Kadar Karbon Terikat & $3,69 \%$ \\
\hline \multicolumn{2}{|c|}{ Jenis Kayu Nangka } \\
\hline Jenis Kadar & $13,34 \%$ \\
\hline Kadar Air & $82,5 \%$ \\
\hline Kadar Zat Terbang & $0,25 \%$ \\
\hline Kadar Abu & 3,64 \\
\hline Kadar Karbon Terikat & \\
\hline \multicolumn{2}{|c|}{ Jenis Kayu Jati } \\
\hline Jenis Kadar & 42,22 \\
\hline Kadar Air & $71,6 \%$ \\
\hline Kadar Zat Terbang & $0,35 \%$ \\
\hline Kadar Abu & 3,71 \\
\hline Kadar Karbon Terikat &
\end{tabular}

Berdasarkan hasil pengujian yang diperoleh dapat kita ketahui bahwa kadar air tertinggi terdapat pada kayu mahoni dengan kadar air $12,24 \%$. Kadar air memiliki peranan yang cukup penting pada nilai kalor dari tiap biomassa. Namun, nilai kalor tidak hanya dipengaruhi oleh kandungan air saja, melainkan kandungan karbon, hidrogen, dan oksigen yang terdapat pada tiap biomassa.

Kadar zat terbang pada kayu mahoni mencapai 83,5 \%. Kadar zat terbang yang tinggi, menyebabkan kayu mahoni akan lebih mudah untuk terbakar.

Untuk kadar abu pada kayu mahoni mencapai $0,57 \%$. Emisi abu yang sedikit akan memudahkan pembersihan sisa pembakaran, karena abu yang ditinggalkan tidak terlalu banyak. Kadar karbon terikat yang terdapat pada kayu mahoni mencapai 3,69 \%. Semakin besar kandungan karbon terikat memungkinkan reaksi pembakaran berjalan dengan lebih baik.

\section{KESIMPULAN}

Dari hasil perancangan, pembuatan dan pengujian pada alat tersebut bisa dibuat kesimpulan yaitu:

1. Tungku (furnace) yang dibuat mampu mencapai suhu $800{ }^{\circ} \mathrm{C}$ dari temperatur $32{ }^{\circ} \mathrm{C}$ dalam waktu 360 menit.

2. Alat yang dibuat bisa digunakan untuk melakukan pengujian.

3. Dari hasil pengujian dengan menggunakan tiga jenis kayu yang berbeda maka jenis kayu yang paling baik adalah kayu mahoni karena kadar air nya paling rendah sekitar $12,24 \%$.

\section{DAFTAR PUSTAKA}

[1] Sugiyono, Agus., Anindhita., Laode M.A. Wahid., Adiarso. 2016. Outlook Energi Indonesia 2016: Pengembangan Energi untuk Mendukung Industri Hijau. Jakarta: Pusat Teknologi Sumber Daya Energi dan Industri Kimia (PTSEIK), 2016.

[2] Mulyasari,Tia.2013. Karakteristik Beberapa Jenis Kayu Sebagai Bahan 
Baku Energi Biomassa. Bogor : ejournal Institut Pertanian Bogor, 2013.

[3] Rahmat, Muhammad Rais. 2015. Perancangan dan Pembuatan Tungku Heat Treatment. Bekasi : e-journal Universitas Islam "45” Bekasi, 2015, Vol. 3.

[4] Hendry Gustar," Perancangan Tungku Mufle untuk proses Heat Treatment Material Logam", Skripsi Tugas Akhir, 2016.
[5] M. Arief Jihan, ' Rancang bangun pemanas air listrik dengan menggunakan Arduino", Skripsi Tugas Akhir, 2019.

[6] Badan Standardisasi Indonesia. 2005. Nilai Ambang Batas (NAB) Zat Kimia di Udara Tempat Kerja. [Online] 2005. Diakses: 11 Februari 2017. http://web.ipb.ac.id. 19-0232-2005. 